\title{
Decomposition Processes of $\beta$ Phase in a Ti-15Zr-4Nb-4Ta Alloy
}

\author{
Sengo Kobayashi ${ }^{1}$, Arihiro Matsuzaki ${ }^{1}{ }^{*}$, Kiyomichi Nakai $^{1}$ and Yoshimitsu Okazaki ${ }^{2}$ \\ ${ }^{1}$ Department of Materials Science and Engineering, Ehime University, Matsuyama 790-8577, Japan \\ ${ }^{2}$ National Institute of Advanced Industrial Science and Technology (AIST), Institute of Mechanical Systems Engineering \\ AIST Tsukuba East, Tsukuba 305-8564, Japan
}

\begin{abstract}
Decomposition processes of $\beta$ phase in a Ti-15Zr-4Nb-4Ta alloy during isothermal holding have been examined mainly by transmission electron microscopy. Specimens solution-treated at $1000^{\circ} \mathrm{C}$ in $\beta$ phase field were held at temperatures between 400 and $600^{\circ} \mathrm{C}$. $\alpha$ phase lath formed in $\beta$ phase during isothermal holding at $600^{\circ} \mathrm{C}$. After holding at $600^{\circ} \mathrm{C}$ for a short duration, remaining $\beta$ phase, untransformed $\beta$ phase into $\alpha$ phase at $600^{\circ} \mathrm{C}$, was transformed into $\alpha^{\prime}$ martensite during quenching into ice-brine. As increasing holding time at $600^{\circ} \mathrm{C}$, remaining $\beta$ phase was transformed into $\alpha^{\prime \prime}$ or athermal $\omega$ phases during quenching. After prolonged holding at $600^{\circ} \mathrm{C}$, remaining $\beta$ phase was not transformed during quenching. Enrichment of $\mathrm{Nb}$, Ta and $\mathrm{Zr}$ into remaining $\beta$ phase occurred with increasing holding time at $600^{\circ} \mathrm{C}$, resulting in the variation of transformation of remaining $\beta$ phase during quenching. Microstructures evolved at 400 and $500^{\circ} \mathrm{C}$ were almost same as those at $600^{\circ} \mathrm{C}$.
\end{abstract}

(Received December 5, 2003; Accepted April 5, 2004)

Keywords: phase decomposition, titanium alloy, biomaterial, athermal $\omega$ phase, transmission electron microscopy

\section{Introduction}

A Ti-6Al-4V ELI alloy has been widely attracted for surgical implant. However, it contains both vanadium, being a strong cytotoxic element ${ }^{1,2)}$ and aluminum, being a suspicious element for causing neurological disorders. ${ }^{3)}$ Newly developed Ti-based biomaterials consist of low cytotoxic elements such as $\mathrm{Zr}, \mathrm{Nb}$, Ta, Pt and Sn. ${ }^{4)} \mathrm{A}$ Ti-15Zr-4Nb-4Ta alloy has been recently developed for a biocompatible material. $^{5,6)}$ The Ti-15Zr-4Nb-4Ta alloy exhibits a good balance of strength and ductility with high corrosion resistance. ${ }^{7-11)}$ Standard specification for the Ti-15Zr-4Nb4Ta alloy for surgical implant application was settled in the JIS T 7401-4. Since required mechanical properties for biomaterials will become severe, microstructures, which affect mechanical properties, should be positively controlled by phase decomposition. There is, however, a little study on the microstructure evolutions in a Ti-15Zr-4Nb-4Ta alloy especially by transmission electron microscopy (TEM). The purpose of present study is to examine microstructure evolutions of $\beta$ phase in a Ti-15Zr-4Nb-4Ta alloy.

\section{Experimental Procedures}

A Ti-15Zr-4Nb-4Ta alloy rod of $16 \mathrm{~mm}$ in diameter was cut into disks of $2 \mathrm{~mm}$ thick. The specimens solution-treated at $1000{ }^{\circ} \mathrm{C}$ for $1.8 \mathrm{ks}$ in $\beta$ phase field were held at temperatures between 400 and $600^{\circ} \mathrm{C}$ in a dynamic $\mathrm{Ar}$ gas atmosphere. Microstructures were examined by both optical and transmission electron microscopies. The specimens for optical microscopy were polished and etched in a $5 \% \mathrm{HF}+20 \% \mathrm{HNO}_{3}+75 \% \mathrm{H}_{2} \mathrm{O}$ reagent. Thin foils for TEM were prepared by twin-jet electropolishing in a $10 \% \mathrm{HClO}_{4}+2 \% \mathrm{C}_{4} \mathrm{H}_{9} \mathrm{OH}+88 \% \mathrm{CH}_{3} \mathrm{OH}$ solution at $-50{ }^{\circ} \mathrm{C}$ on the voltage of $50 \mathrm{~V}$, and examined in an analytical JEM 2000EX microscope operated at $200 \mathrm{kV}$. Composition analysis by energy dispersive X-ray spectroscopy (EDS) was

*Graduate Student, Ehime University performed. The k-factor defined by the Cliff-Lorimer method $^{12)}$ was estimated in the limit of a thin film specimen and determined by the EDS measurement on the Ti-15Zr$4 \mathrm{Nb}-4 \mathrm{Ta}$ alloy whose chemical composition was already known. Hardness was measured using a Vickers hardness tester.

\section{Results}

\subsection{Optical microscopic observations}

Figures 1(a)-(c) show the optical micrographs taken from specimens held at 600,500 and $400{ }^{\circ} \mathrm{C}$ for $3.6 \mathrm{ks}$, respectively. Laths of about 1-2 $\mu \mathrm{m}$ wide formed in the specimen held at $600{ }^{\circ} \mathrm{C}$ for $3.6 \mathrm{ks}$. As we will explain later, the lath was $\alpha$ phase. The laths were also observed in the specimen held at 400 and $500{ }^{\circ} \mathrm{C}$ for $3.6 \mathrm{ks}$. As the holding temperature decreased, width of the laths became small. The laths formed from grain boundary were sometimes accompanied with allotriomorph as indicated by arrows in Fig. 1(c). Furthermore, interface of the lath was not sharp as observed in Fig. 1(a). The laths probably formed by diffusional transformation during holding at temperatures between 400 and $600{ }^{\circ} \mathrm{C}$. The size of the laths did not much change during isothermal holding over $3.6 \mathrm{ks}$.

\subsection{TEM observations}

Figure 2(a) is the bright field image taken from specimen held at $600^{\circ} \mathrm{C}$ for $3.6 \mathrm{ks}$, showing formation of coarse laths of about $1 \sim 2 \mu \mathrm{m}$ wide. The coarse laths correspond to those observed in Fig. 1(a). The coarse laths contain little defects such as dislocations, stacking faults and twin. Figure 2(b) is the magnified image of the area enclosed with a rectangle in Fig. 2(a). Fine laths of about $20 \mathrm{~nm}$ wide can be observed. Figure 2(c) is the selected area diffraction (SAD) pattern of Fig. 2(b). Diffraction spots in Fig. 2(c) can be indexed as hcp structure denoted as $\alpha$ and $\alpha^{\prime}$. Figure 2(d) is the dark field image taken with $(\overline{1} 10 \overline{1})_{\alpha^{\prime}}$ reflection, showing the fine laths. Magnified image of the area indicated by a white rectangle in Fig. 2(d) is inserted on the right upper corner. It should be 

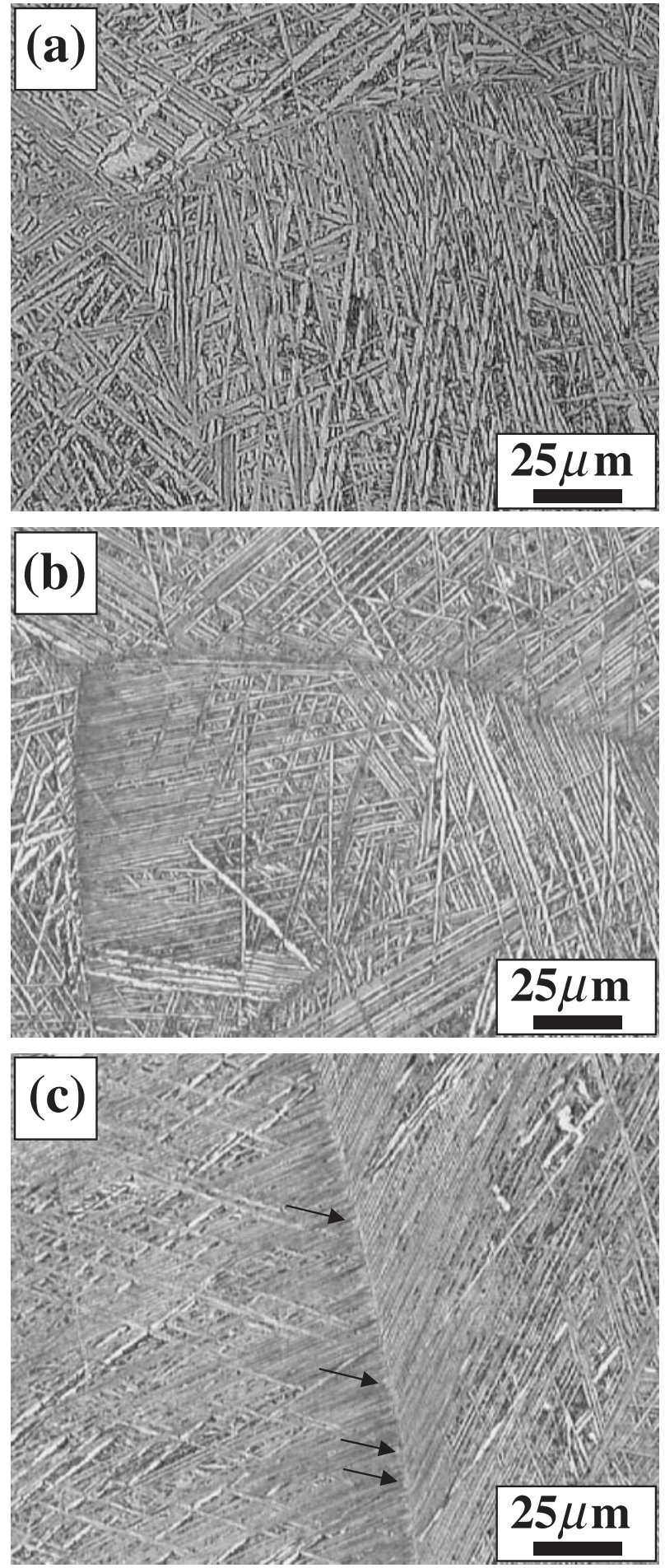

Fig. 1 Optical micrographs taken from specimens held at (a) 600, 500 and $400^{\circ} \mathrm{C}$ for $3.6 \mathrm{ks}$, respectively.

noted that the fine laths contained many defects as indicated by white arrows. Examining dark field images taken with reflections in Fig. 2(c) revealed that the coarse and the fine laths related to $\alpha$ and $\alpha^{\prime}$ diffraction spots, respectively. Since the coarse laths contained little defects, they probably formed in $\beta$ phase by diffusional transformation during holding at $600^{\circ} \mathrm{C}$ for $3.6 \mathrm{ks}$. On the other hand, since the fine lath contained many defects, they probably formed from remaining $\beta$ phase by martensitic transformation during quenching
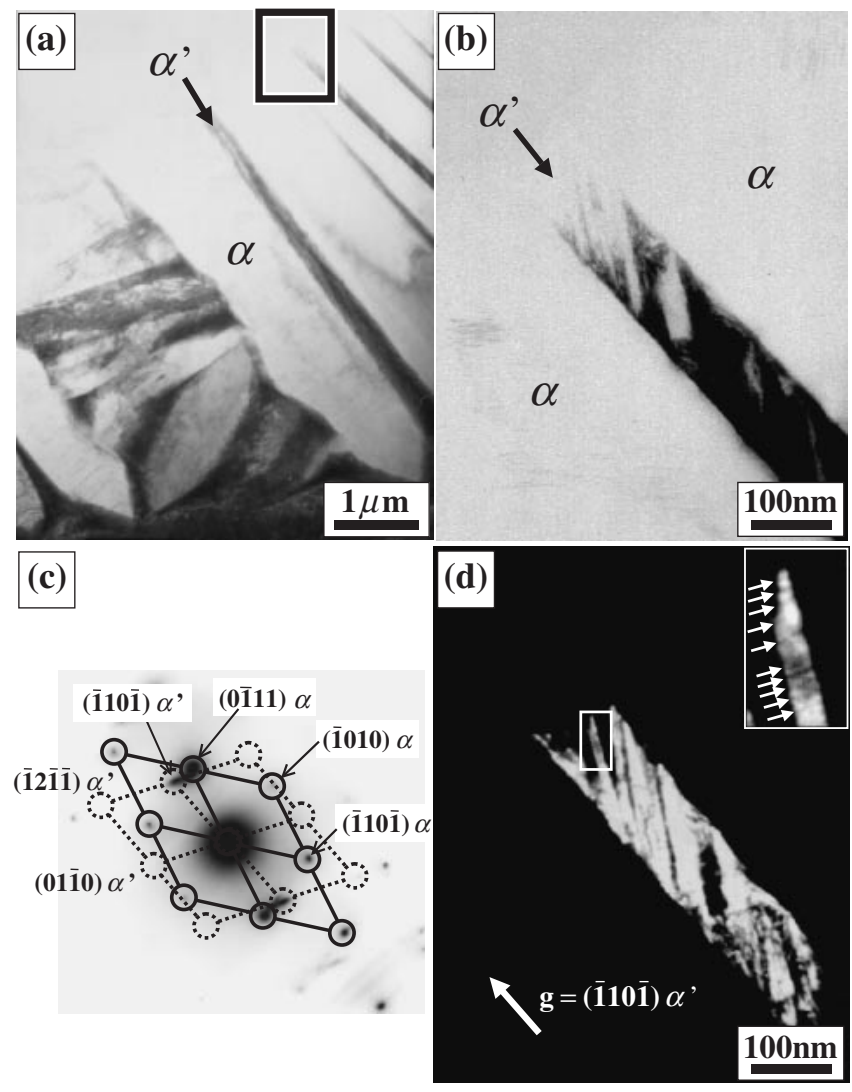

Fig. 2 TEM micrographs taken from specimen held at $600^{\circ} \mathrm{C}$ for $3.6 \mathrm{ks}$ : (a) the bright field image, (b) the magnified image of area indicated by a rectangle in (a), (c) the selected area diffraction pattern and (d) the dark field image using the $(\overline{1} 10 \overline{1})_{\alpha^{\prime}}$ reflection, respectively.

into ice-brine. In the present study, remaining $\beta$ phase represents untransformed $\beta$ phase at $600^{\circ} \mathrm{C}$. Figure 3 shows the TEM micrographs taken from specimen held at $600^{\circ} \mathrm{C}$ for $86.4 \mathrm{ks}$; (a) the bright field image, (b) the magnified image of the area enclosed with a rectangle in (a) and (c) the SAD pattern of (b), respectively. The key diagram in Fig. 3(c) revealed that $\alpha$ and $\alpha^{\prime \prime}$ phases co-existed. The $\alpha$ phase laths formed during holding at $600^{\circ} \mathrm{C}$ for $86.4 \mathrm{ks}$. Figure 3(d) shows the dark field image taken with $(012)_{\alpha^{\prime \prime}}$ reflection. The $\alpha^{\prime \prime}$ phase formed between $\alpha$ phase laths where $\beta$ phase probably existed at $600^{\circ} \mathrm{C}$. As in the case of $\alpha^{\prime}$ phase formation, the $\alpha^{\prime \prime}$ phase would form from remaining $\beta$ phase during quenching into ice-brine. $\alpha^{\prime \prime}$ phase formation during quenching was also observed in Ti-Nb binary system. ${ }^{13-15}$ ) Figure 4 shows TEM micrographs taken from specimen held at $600^{\circ} \mathrm{C}$ for $86.4 \mathrm{ks}$; (a) the bright field image, (b) the magnified image of the area enclosed with a rectangle in (a) and (c) the SAD pattern of (b), respectively. Key diagram in Fig. 4(c) revealed that $\alpha, \beta$ and $\omega$ phases co-existed. Figure 4(d) shows the dark field image taken with $(01 \overline{1} 1)_{\omega 1}$ reflection. Fine $\omega$ particles of about $5 \mathrm{~nm}$ in diameter were dispersed in $\beta$ phase homogeneously. $(\beta+\omega)$ phases existed between $\alpha$ phase laths. Such $\omega$ precipitation ${ }^{16-33)}$ has also been observed in Ti based alloys. Since the holding temperature, $600^{\circ} \mathrm{C}$ is expected to be too high to form thermal $\omega$ phase, ${ }^{31)}$ the $\omega$ particles observed in Fig. 4(d) were athermal $\omega$ phase formed during quenching into ice-brine. Stereo- 

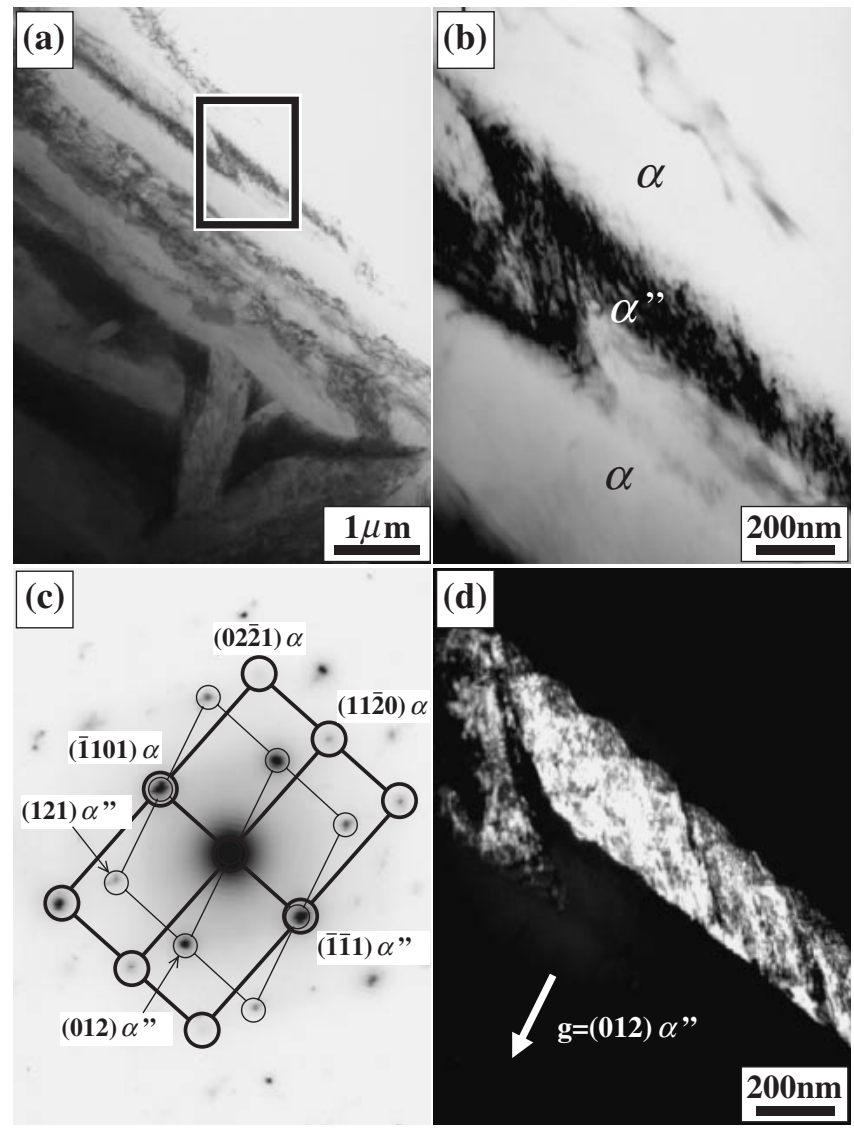

Fig. 3 TEM micrographs taken from specimen held at $600^{\circ} \mathrm{C}$ for $86.4 \mathrm{ks}$ : (a) the bright field image, (b) the magnified image of area indicated by a rectangle in (a), (c) the selected area diffraction pattern and (d) the dark field image using the $(012)_{\alpha^{\prime \prime}}$ reflection, respectively.

graphic analysis of the diffraction pattern in Fig. 4(c) revealed the orientation relationship between $\beta$ and $\omega$ was of the Bagaryatskii ${ }^{17)}$ one. The above results shown in Figs. 3 and 4 indicate that remaining $\beta$ phase decomposes into $\alpha^{\prime \prime}$ or $\omega$ phases during quenching in different regions of the specimen held at $600^{\circ} \mathrm{C}$ for $86.4 \mathrm{ks}$. Figure 5(a) shows the bright field image taken from specimen held at $600^{\circ} \mathrm{C}$ for $172.8 \mathrm{ks}$. $\beta$ phases with and without $\omega$ phase existed between $\alpha$ phase laths, observed as black bands in Fig. 5(a). SAD patterns in Figs. 5(b) and (c) were obtained from the area indicated by circles A and B in Fig. 5(a), respectively. Reflections from $\omega$ phase were clearly observed in Fig. 5(b), while they were not observed in Fig. 5(c). The dark field image in Fig. 5(d) taken with (1011) $)_{\omega 1}$ reflection in (b) shows fine athermal $\omega$ particles dispersed in $\beta$ phase. After holding at $600^{\circ} \mathrm{C}$ for $172.8 \mathrm{ks}$, one of remaining $\beta$ phase was not transformed during quenching as shown in Fig. 5(e). Stereographic analysis of the diffraction pattern in Fig. 5(c) revealed that the orientation relationship between $\alpha$ and $\beta$ phases was of the Burgers, $[\overline{1} 2 \overline{1} 0]_{\alpha} \|[111]_{\beta}$ and $(0001)_{\alpha} \|(0 \overline{1} 1)_{\beta}$.

\subsection{Vickers hardness measurements}

Variation of hardness with holding time at temperatures between 400 and $600^{\circ} \mathrm{C}$ is shown in Fig. 6. Hardness decreased as holding temperature increased. The hardness at
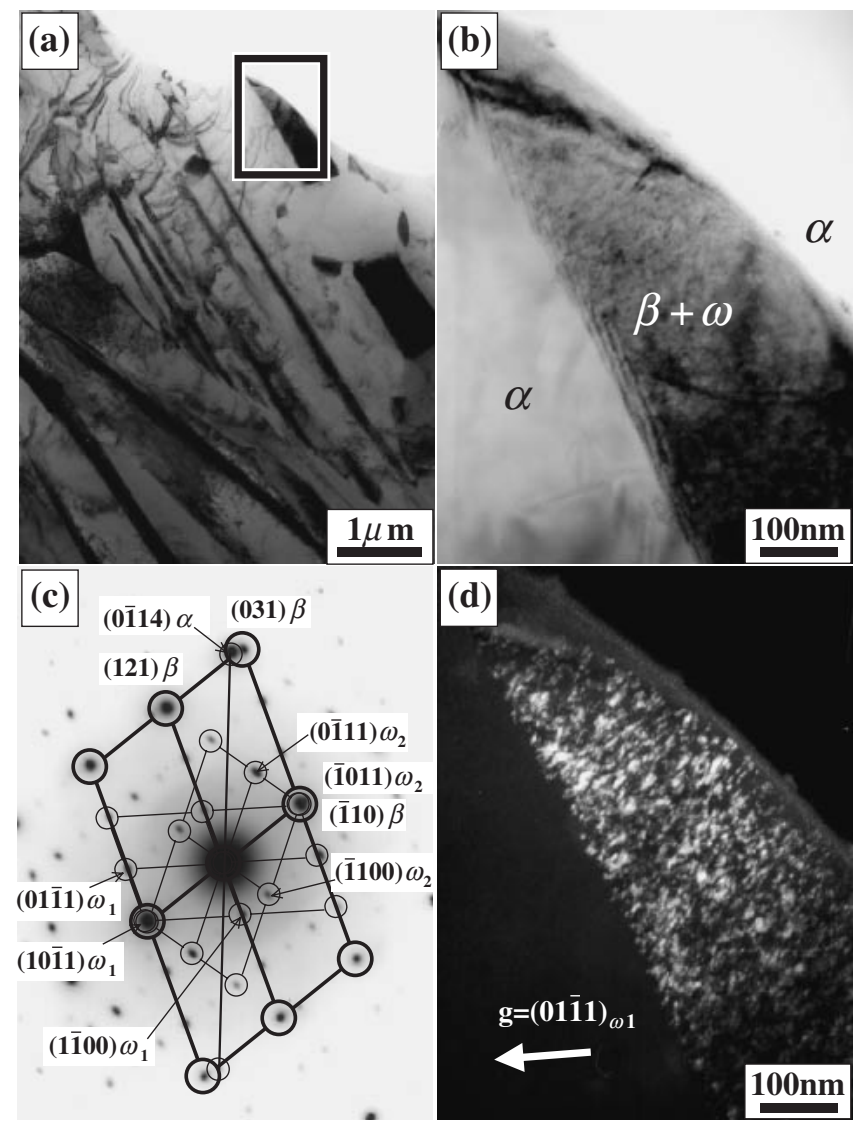

Fig. 4 TEM micrographs taken from specimen held at $600^{\circ} \mathrm{C}$ for $86.4 \mathrm{ks}$ : (a) the bright field image, (b) the magnified image of area indicated by a rectangle in (a), (c) the selected area diffraction pattern and (d) the dark field image using the $(01 \overline{1} 1)_{\omega 1}$ reflection, respectively.

each temperature did not much change by holding time. Although remaining $\beta$ phase was transformed into various phases during quenching depending on the holding time at $600^{\circ} \mathrm{C}$, it makes little effect on hardness. Hardness might be dominated by the size of $\alpha$ phase laths formed during holding. The size of $\alpha$ phase laths did not much change during holding, resulting in little change in hardness. Since $\alpha$ phase laths formed at $400^{\circ} \mathrm{C}$ were finer than those formed at $600^{\circ} \mathrm{C}$, the hardness at $400^{\circ} \mathrm{C}$ is higher than that at $600^{\circ} \mathrm{C}$.

\section{Discussion}

Coarse $\alpha$ phase laths were formed in $\beta$ phase during holding at $600^{\circ} \mathrm{C}$. Remaining $\beta$ phase changed into various phases, such as $\alpha^{\prime}, \alpha^{\prime \prime}, \omega$ and $\beta$ (unchanged) during quenching into ice-brine depending on holding time at $600^{\circ} \mathrm{C}$. Remaining $\beta$ phase in the specimen held for a short duration changed into $\alpha^{\prime}$ phase during quenching. As increasing holding time, remaining $\beta$ phase changed into $\alpha^{\prime \prime}$ phase or athermal $\omega$ phase during quenching. After prolonged holding, remaining $\beta$ phase did not change during quenching. Moffat and Larbalestier ${ }^{30,31)}$ revealed that in Ti-Nb binary alloys $\beta$ phase changed into $\alpha^{\prime}, \alpha^{\prime \prime}$ and $\omega$ phases during quenching with increasing content of $\mathrm{Nb}$. In order to reveal such compositional effects on $\beta$ phase transformation during quenching, the composition analyses of phases were performed by EDS. Figure 7 is the magnified image of Fig. 5(a) showing co- 


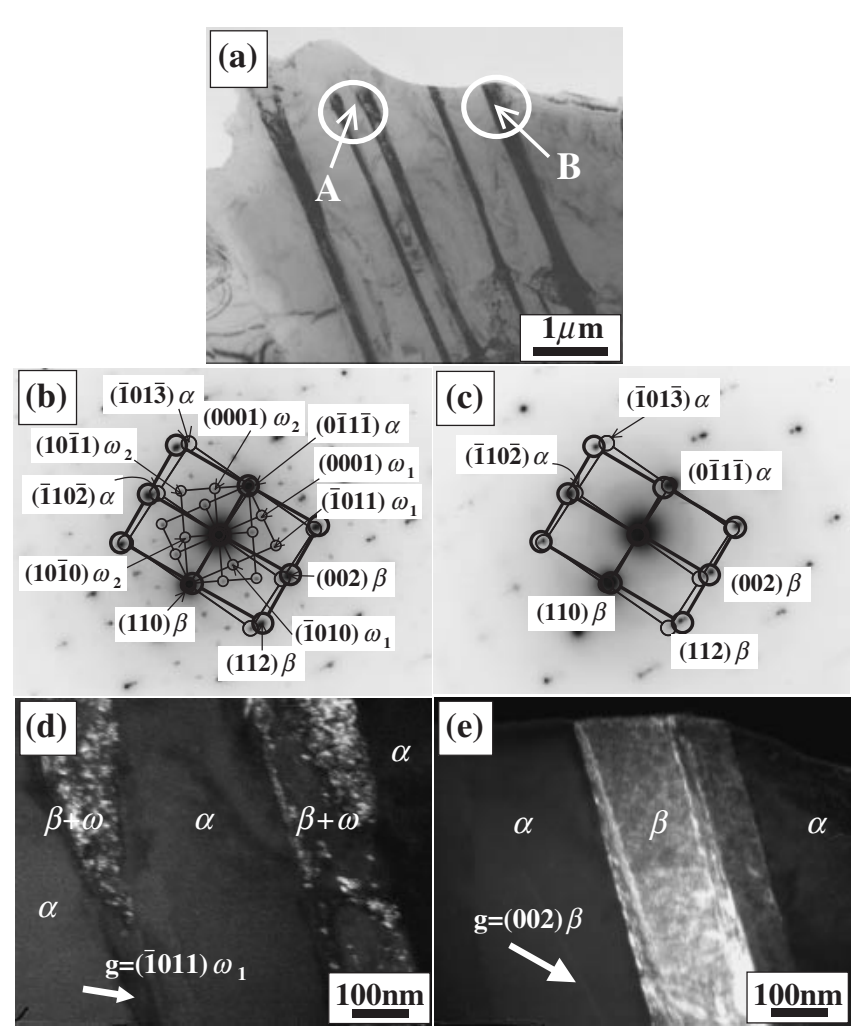

Fig. 5 TEM micrographs for the specimen held at $600^{\circ} \mathrm{C}$ for $172.8 \mathrm{ks}$ : (a) the bright field image, (b) the selected area diffraction pattern of the area-A in (a), (c) the selected area diffraction pattern of the area-B in (a), (d) the dark field image using the $(10 \overline{1} 1)_{\omega 1}$ reflection in (b) and (e) the dark field image using the $(002)_{\beta}$ reflection in (c), respectively.

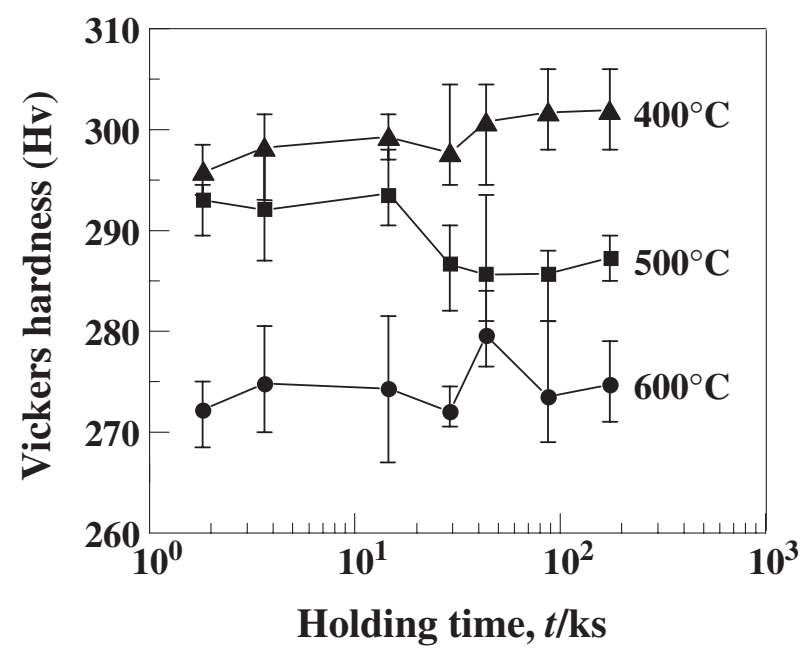

Fig. 6 Variation of hardness with holding time at temperatures between 400 and $600^{\circ} \mathrm{C}$.

existence of $\alpha,(\beta+\omega)$ and $\beta$ phases. The numbered circles in the figure show analyzed sites for chemical composition, whose values (mass \%) are listed in the table. Condensation of $\mathrm{Nb}$, Ta and $\mathrm{Zr}$ occurred in both $(\beta+\omega)$ and $\beta$ phase regions instead of reduction of these elements in $\alpha$ phase. The condensation of $\mathrm{Nb}$, Ta and $\mathrm{Zr}$ in $\beta$ phase is greater than that in $(\beta+\omega)$ phase. It is well known that both $\mathrm{Nb}$ and $\mathrm{Ta}$ are potent $\beta$ phase stabilizers. Furthermore, according to the Ti$\mathrm{Zr}$ binary phase diagram, $\mathrm{Zr}$ is also expected to act as $\beta$ phase

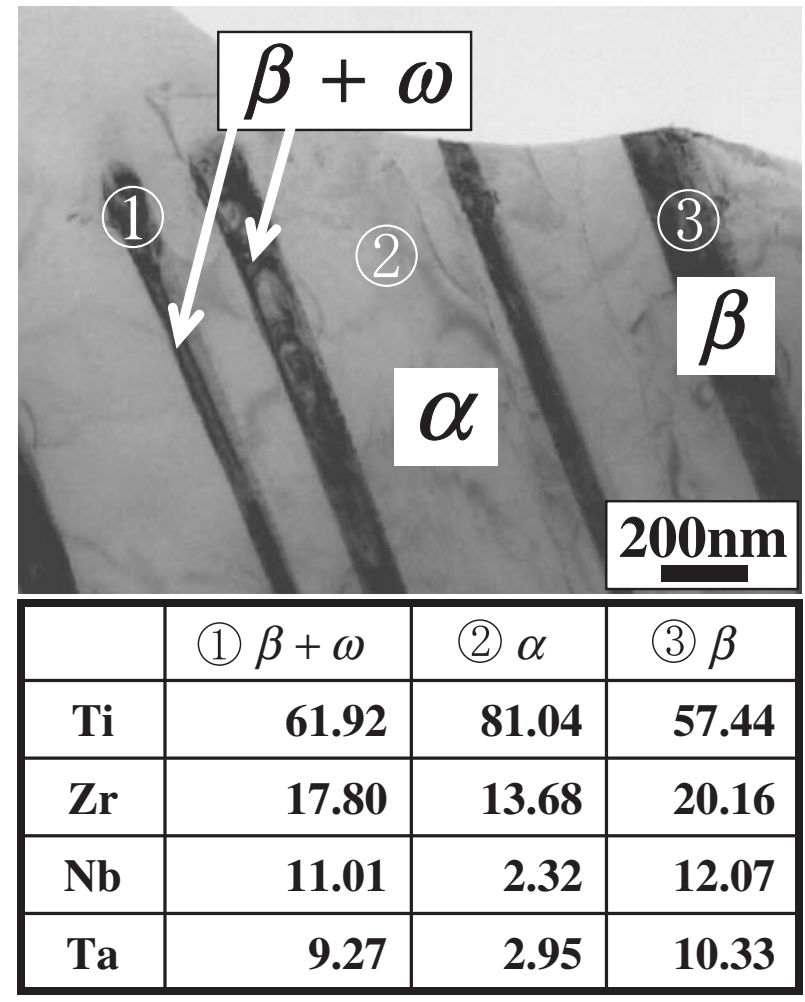

Fig. 7 TEM micrograph for the specimen aged at $600^{\circ} \mathrm{C}$ for $172.8 \mathrm{ks}$. The $(\beta+\omega)$ and $\beta$ phases can be observed between $\alpha$ laths. The numbered circles in the figure show the analyzed sites for the solute composition, whose values are tabulated in the inserted table.

stabilizer. ${ }^{34)}$ The enrichment of $\mathrm{Nb}$, Ta and $\mathrm{Zr}$ into remaining $\beta$ phase occurred during holding at $600^{\circ} \mathrm{C}$ results in various transformations of remaining $\beta$ phase during quenching. Remaining $\beta$ phase was transformed during quenching in the order of $\beta \rightarrow \alpha^{\prime}, \beta \rightarrow \alpha^{\prime \prime}, \beta \rightarrow \omega, \beta \rightarrow \beta$ (untransformed) with increasing content of $\mathrm{Nb}$, Ta and $\mathrm{Zr}$ in remaining $\beta$ phase. It should be noted that formation of $\alpha$ phase laths during holding was accompanied by compositional change, indicating $\alpha$ phase laths formed during holding by diffusional transformation.

\section{Conclusions}

The decomposition processes of $\beta$ phase in a Ti-15Zr-4Nb4Ta alloy during isothermal holding and quenching into icebrine are summarized as follows.

(1) $\alpha$ phase laths formed in $\beta$ phase during holding. Remaining $\beta$ phase in the early stage of holding was transformed into $\alpha^{\prime}$ phase during quenching.

(3) As increasing holding time, $\alpha^{\prime \prime}$ and athermal $\omega$ phases formed during quenching. The orientation relationship between $\beta$ and $\omega$ phases is of the Bagaryskii one.

(4) Remaining $\beta$ phase was not transformed during quenching after prolonged holding at $600^{\circ} \mathrm{C}$. The orientation relationship between $\alpha$ and $\beta$ phases is of the Burgers one.

(5) Enrichment of $\mathrm{Nb}$, Ta and $\mathrm{Zr}$ into remaining $\beta$ phase occurred with increasing in holding time, resulting in various transformations of remaining $\beta$ phase into $\alpha^{\prime \prime}$ and athermal $\omega$ phases, rather than $\alpha^{\prime}$ phase. Finally, 
remaining $\beta$ phase was not transformed during quenching by the further enrichment.

\section{Acknowledgments}

The authors wish to express their sincere thanks to a Grantin-Aid for Scientific Research, the Ministry of Education, Science, Sports and Culture of Japan. Thanks are also due to the INCS, Ehime University for using transmission electron microscope for observation.

\section{REFERENCES}

1) M. Semlitsch, F. Staub, H. Webber: Biomed. Tech. 30 (1985) 334-339.

2) Y. Okazaki, Y. Ito, T. Tateishi and A. Ito: J. Japan Inst. Metals 59 (1995) 108-115.

3) D. P. Perl and A. R. Brody: Science 208 (1980) 297-299.

4) H. Kawahara: Bull. J. Inst. Met. 31 (1992) 1033-1039.

5) Y. Okazaki, Y. Ito, K. Kyo, T. Tateishi: Mater. Sci. Eng. A231 (1996) 138-147.

6) Y. Okazaki, S. Rao, T. Tateishi and Y. Ito: Mater. Sci. Eng. A234 (1998) 250-256.

7) Y. Okazaki, Y. Ito, T. Tateishi, A. Ito: J. Japan Inst. Metals 59 (1995) 108-115.

8) Y. Okazaki, M. Ota, Y. Ito, T. Tateishi: J. Japan Inst. Metals 59 (1995) 229-236.

9) Y. Okazaki, K. Kyo, Y. Ito, T. Tateishi: J. Japan Inst. Metals 59 (1995) 1061-1069.

10) Y. Okazaki, K. Kyo, Y. Ito, T. Tateishi: J. Japan Inst. Metals 59 (1995) 1070-1077.

11) Y. Okazaki, K. Kyo, Y. Ito, T. Tateishi: J. Japan Inst. Metals 59 (1995) 1078-1083.

12) G. Cliff and G. W. Lorimer: J. Microsc. 103 (1975) 203-207.
13) T. Ahmed and H. J. Rack: J. Mater. Sci 31 (1996) 4267-4276.

14) D. L. Moffat and D. C. Larbalestier: Metall. Trans. A 19A (1988) 1677-1686.

15) M. Ikeda, S. Komatsu, T. Sugimoto and K. Kamei: J. Japan Inst. Metals 53 (1989) 664-671.

16) J. M. Silcock: Acta Metall. 6 (1958) 481-493.

17) D. de Fontaine:Metall. Trans. A 19A (1988) 169-175.

18) D. de Fontaine: Acta Metall. 18 (1970) 275-279.

19) J. C. Williams, D. de Fontain and N. E. Paton: Metall. Trans. 4 (1973) 2701-2708.

20) H. E. Cook: Acta Metall. 21 (1973) 1445-1449.

21) H. E. Cook: Acta Metall. 22 (1974) 239-247.

22) E. Sukedai and H. Hashimoto: J. Japan Inst. Metals. 56 (1992) 13921400 .

23) H. Matsumoto, E. Sukedai, H. Yagi and H. Hashimoto: J. Japan Inst. Metals. 65 (2001) 374-381.

24) D. de Fontaine and R. Kikuchi: Acta Metall. 27 (1979) 1139-1146.

25) S. L. Sass: Acta Metall. 17 (1969) 813-820.

26) G. J. Cuello, A. F. Guillermet and J. R. Granada: Z. Metallk. 89 (1998) 823-827.

27) G. Aurelio and A. F. Guillermet: J. Alloys Comp. 292 (1999) 31-37.

28) G. Aurelio and A. F. Guillermet: Z. Metallk. 91 (2000) 35-42.

29) Y. Takemoto, M. Hida and A. Sakakibara: J. Japan Inst. Metals 57 (1993) 261-267.

30) D. L. Moffat and D. C. Larbalestier: Metall. Trans. A 19A (1988) 1677-1686.

31) D. L. Moffat and D. C. Larbalestier: Metall. Trans. A 19A (1988) 1687-1694.

32) S. Kobayashi, S. Nakagawa, K. Nakai, Y. Ohmori: Mater. Trans. 43 (2002) 2956-2963.

33) M. Ikeda, S. Komatsu, T. Sugimoto and K. Kamei: J. Japan Inst. Metals 52 (1988) 1206-1211.

34) T. B. Massalski, H. Okamoto, P. R. Subramanian and L. Kacprzak: BINARY ALLOY PHASE DIAGRAM 2nd ed., (ASM International, Ohio, 1990) 3502-3503. 